\title{
Ghanges of the Radioactive Iodine Uptake and in the Iodoamino Acids Pattern of Thyroid in Rats in the Course of Advancement of Iodine Deficiency*
}

\author{
Junichi Suwa, Shuichi Kimura and Tatsuo Koyanagi $\dagger$ \\ Laboratory of Nutrition, Faculty of Agriculture, Tohoku \\ University, Sendai
}

\begin{abstract}
Suwa, J., Krmura, S. and Koxanagi, T. Changes of the Radioactive Iodine Uptake and in the Iodoamino Acids Pattern of Thyroid in Rats in the Course of Advancement of Iodine Deficiency. Tohoku J. exp. Med., 1971, 104 (3), 301-304 - Hourly changes of ${ }^{131} \mathrm{I}$ uptake and the changes in several indices of thyroid at different time intervals after beginning of an iodine deficient diet with or without propylthiouracil were determined. An amino acid mixture was used as the protein source in the present experiments. The magnitude of iodine uptake and the ratio of monoiodotyrosine to diiodotyrosine increased according to the length of time on low iodine diet. The earlier appearance and more enlargement of peak of the ratio of monoiodotyrosine to diiodotyrosine in rats treated with small dose of propylthiouracil than in those untreated suggested that propylthiouracil might also bring about the lack of iodine by inhibiting the iodination at substrate level. iodine deficiency; thyroid; propylthiouracil
\end{abstract}

The most common techniques for determining the activity of the thyroid gland is to inject a tracer dose of radioactive iodine ( $\left.{ }^{131} \mathrm{I}\right)$ to animals and subsequently determine the magnitude of ${ }^{131} \mathrm{I}$ uptake in thyroid, the ratio of monoiodotyrosine (MIT) to diiodotyrosine (DIT) and the amount of iodothyronines within the gland. Since the magnitude of iodine uptake and MIT/DIT ratio are affected by the degree of iodine deficiency and also by the presence of an antithyroid hormone, we measured these values in the course of advancement of iodine deficiency in rats fed on low iodine diet (LID) with or without propylthiouracil (PTU).

\section{Materials and Methods}

Fifty female albino rats, Wistar strain, weighing about $100 \mathrm{~g}$ were fed on LID. The composition of the diet (in per cent) was as follows: amino acid mixture (Rogers and Harper 1965), 17; soybean oil, 2; salts mixture (Rogers and Harper 1965) (excluding iodide), 4; vitamin mixture (Rogers and Harper 1965), 1 ; and dextrin to make 100 per cent. Half the animals were fed on the diet of the same composition but supplemented with 50 $\mu \mathrm{g}$ PTU. The diets were made into paste by mixng vigorously the dry diet with an equal quantity of boiling distilled water. The use of the amino acid mixture in place of protein

Received for publication, December 28, 1970.

* This investigation was supported in part by Grant FG-Ja-125 from the U.S. department of Agriculture.

$\dagger$ Present address: Laboratory of Food and Nutrition, Department of Education, Iwate University, Morioka. 
prevented the inclusion in the diet of iodine and any goitrogens or thyroid affecting compounds which may be contained in protein. Distilled water and diets were given ad libitum.

The animal laboratory was maintained at $25^{\circ} \mathrm{C}$ and at $65 \%$ relative humidity. Iodine uptake was determined as follows. Each rat received a single intraperitoneal injection of $15 \mu \mathrm{Ci}$ carrier-free ${ }^{131} \mathrm{I}$ and killed by exsanguination under anesthesia with ether at desired intervals following injection, then thyroids were removed and weighed. The ${ }^{131} I$ uptake was obtained by comparison with appropriated standards in a well-type scintillation counter (Premachandra 1966). Chromatographic analysis of labeled thyroid was conducted essentially in the same way as described by Inoue and Taurog (1968).

\section{Results and Discussion}

The effect of advancement of iodine-deficiency on hourly change of ${ }^{131} \mathrm{I}$ uptake was shown in Table 1. The iodine uptake exhibited a peak within $24 \mathrm{hr}$ in both groups of rats. And in rats fed with PTU the peak appeared earlier than in those without PTU. Along with the progress of iodine deficiency during the observation period of 5 weeks the peak appeared earlier in the deficient rats than in those untreated and also higher values were seen in the deficient rats.

TABLE 1. Hourly changes of ${ }^{131} I$ uptake in per cent at different time intervals after beginning of a low iodine diet with or without PTU

\begin{tabular}{|c|c|c|c|c|c|c|c|c|c|c|c|}
\hline \multirow{2}{*}{$\begin{array}{l}\text { Weeks of } \\
\text { feeding }\end{array}$} & \multirow{2}{*}{ Diet } & \multicolumn{10}{|c|}{ Hours after ${ }^{131} I$ injection } \\
\hline & & 1 & 2 & 3 & 4 & 5 & 6 & 8 & 10 & 12 & 24 \\
\hline \multirow[t]{2}{*}{1} & LID & 12.2 & 17.2 & & 22.0 & & 26.0 & & & 27.4 & 25.7 \\
\hline & LID, PTU & 13.2 & 16.3 & & 20.0 & & 19.3 & & & 18.4 & 12.0 \\
\hline \multirow[t]{2}{*}{2} & LID & 16.9 & 25.2 & 27.3 & 34.9 & 35.2 & 39.4 & 41.3 & & 43.7 & 35.8 \\
\hline & LID, PTU & 38.6 & 48.9 & 54.5 & 55.3 & 52.8 & 53.2 & 49.7 & & 43.5 & 27.5 \\
\hline \multirow[t]{2}{*}{3} & LID & 23.3 & 34.5 & 42.5 & 47.7 & 52.9 & 54.9 & 53.8 & 51.8 & 51.6 & 38,9 \\
\hline & LID, PTU & 54.6 & 65.9 & 68.8 & 66.4 & 66.3 & 64.0 & 57.5 & 53.0 & 49.9 & 38.6 \\
\hline \multirow[t]{2}{*}{4} & LID & 44.1 & 54.4 & 57.6 & 58.3 & 56.6 & 51.9 & 48.7 & 45.6 & & 26.9 \\
\hline & LID, PTU & 55.8 & 67.2 & 71.1 & 69.3 & 68.4 & 67.8 & 60.9 & 61.7 & & 35.9 \\
\hline \multirow[t]{2}{*}{5} & LID & 36.9 & 44.2 & 45.6 & 41.2 & & 37.6 & 35.0 & 33.0 & & 22.4 \\
\hline & LID, PTU & 48.8 & 56.2 & 57.4 & 51.2 & & 47.0 & 43.4 & 41.2 & & 27.4 \\
\hline
\end{tabular}

Radioiodine uptake of rat thyroids in relation to the period of iodine deficiency was studied by Studer and Greer (1968). They found that at approximately 3 weeks after the beginning of LID the radioiodine uptake reached a value of approximately $70 \%$ and the value tended to gradually increase until 28 th week of examination. The results of the present experiments are consistent with their results except that in the present experiments the magnitude of radioiodine uptake in both groups decreased at the fifth week. The reason for this decrease is not explainable at present.

Weekly changes of the weight of thyroid and of the radioactivity in each iodoamino acid $24 \mathrm{hr}$ after ${ }^{131} \mathrm{I}$ administration in rats fed on LID with or without PTU were shown in Table 2. While in the absence of PTU the ratio of MIT to DIT increased steadily during advancement of iodine deficiency, in the presence of PTU the values were always higher than in rats fed on LID alone and the values 
TABLE 2. Changes in several indices of thyroid function at different time intervals after beginning of a low iodine diet with or without PTU (mean values of 5 rats)

\begin{tabular}{|c|c|c|c|c|c|c|c|c|}
\hline \multirow{2}{*}{$\begin{array}{c}\text { Weeks of } \\
\text { feeding }\end{array}$} & \multirow{2}{*}{ Diet } & \multirow{2}{*}{$\begin{array}{l}\text { Thyroid weight } \\
(\mathrm{mg} / 100 \mathrm{~g} \mathrm{B.W.*})\end{array}$} & \multicolumn{6}{|c|}{24 hr ${ }^{131}$ I uptake ( $\%$ total $\left.{ }^{131} I\right)$} \\
\hline & & & Origint & $\mathbf{I}$ & MIT & DIT & $\mathrm{T}_{3}+\mathrm{T}_{4}$ & MIT/DIT \\
\hline \multirow[t]{2}{*}{1} & LID & 8.5 & 3.3 & 8.1 & 28.0 & 36.3 & 24.3 & 0.77 \\
\hline & LID, PTU & 14.3 & 5.9 & 11.5 & 31.9 & 35.7 & 14.9 & 0.89 \\
\hline \multirow[t]{2}{*}{2} & LID & 9.1 & 6.3 & 8.0 & 30.8 & 29.3 & 14. 9 & 1.05 \\
\hline & LID, PTU & 33.6 & 7.8 & 14.6 & 48.5 & 17.6 & 11.5 & 2.76 \\
\hline \multirow[t]{2}{*}{3} & LID & 9.1 & 1.5 & 5.4 & 43.3 & 28.5 & 21.3 & 1.52 \\
\hline & LID, PTU & 35.2 & 1.9 & 8.1 & 67.6 & 18.2 & 4.2 & 3. 72 \\
\hline \multirow[t]{2}{*}{4} & LID & 12.6 & 1.9 & 6.3 & 56.0 & 25.4 & 10.3 & 2.20 \\
\hline & LID, PTU & 35.5 & 1.6 & 8.0 & 67.7 & 18.6 & 4. 0 & 3.64 \\
\hline \multirow[t]{2}{*}{5} & LID & 15.8 & 0.1 & 5.0 & 61.3 & 25.1 & 8.4 & 2.44 \\
\hline & LID, PTU & 33.0 & 0.1 & 7.6 & 68.0 & 21.3 & 2.6 & 3.19 \\
\hline
\end{tabular}

* Body weight.

$\dagger$ Origin means the amount of ${ }^{131} \mathrm{I}$ which remained unmoved on paperchromatography.

increased until the third week. The synthesis of iodothyronins $\left(\mathrm{T}_{3}+\mathrm{T}_{4}\right)$ decreased to a very low level at the third week in PTU treated rats while in those fed on LID it remained at a fairly high level.

The increase of MIT/DIT ratio has been postulated to be due to the inhibition of synthesis of DIT from MIT. And iodine deficiency has been reported to lead to the in vivo formation of more MIT than DIT (Gross and Pitt-Rivers 1954), namely, to the increase of MIT/DIT ratio. The increase of MIT/DIT ratio occurred more remarkably when the deficient rats were also given a small quantity of PTU.

Pittman et al. (1963) forwarded the idea that PTU also brings about the lack of iodine by inhibiting iodination at the substrate level as same as in the case of the over-all lack of iodine in diet. Studer and Green (1967) thought that PTU, by blocking the binding of iodide with organic substances, markedly reduced the ability of the thyroid to retain iodide which entered the gland. This iodide is therefore rapidly lost from the body, primarily through renal excretion. Iodine deficiency is thus produced more quickly with a diet insufficient in iodine if PTU is additionally administered. The earlier appearance and more remarkable enlargement of peak of the MIT/DIT ratio in rats treated with a small dose of PTU than in those untreated in the present experiments are consistent with the hypothesis mentioned above.

\section{Acknowledgment}

We wish to thank Mr. Tadayuki Tomita for his technical assistance. Thanks are also due to Ajinomoto Co., Inc. for the gift of amino acids.

\section{References}

1) Gross, J. \& Pitt-Rivers, R. Triiodothyronine in relation to thyroid physiology. Recent Progress in Hormon Research, 1954, 10, 109-128.

2) Inoue, K. \& Taurog, A. Acute and chronic effects of iodide on thyroid radioiodine metabolism in iodine-deficient rats. Endocrinology, 1968, 83, 279-290. 
3) Pittman, C.S., Liu, A. \& Jones, E.E. Hormone synthesis by a transplantable thyroid tumor in mice. Endocrinology, 1963, 73, 403-409.

4) Premachandra, B.N. An improved technique for thyroidal ${ }^{131} I$ determination in the small laboratory animal. Endocrinology, 1966, 78, 254-260.

5) Rogers, Q.R. \& Harper, A.E. Amino acid diets and maximal growth in the rat. J. Nutr., 1965, 87, 267-273.

6) Studer, H. \& Greer, M.A. Thyroid function during the rebound phase following the discontinuation of antithyroid drugs. Endocrinology, 1967, 80, 52-60.

7) Studer, H. \& Greer, M.A. The Regulation of Thyroid Function in Iodine Deficiency. Huber Publishing Co., Bern and Stuttgart, 1968. 